\title{
Effect of daidzein, 4-methylbenzylidene camphor or estrogen on gastrocnemius muscle of osteoporotic rats undergoing tibia healing period
}

\author{
Marina Komrakova, Carsten Werner ${ }^{1}$, Michael Wicke ${ }^{1}$, Ba Tiep Nguyen ${ }^{2}$, Stephan Sehmisch, \\ Mohammad Tezval, Klaus Michael Stuermer and Ewa Klara Stuermer \\ Department of Trauma Surgery and Reconstructive Surgery, University of Goettingen, Robert-Koch Strasse 40, 37075 Goettingen, Germany \\ ${ }^{1}$ Institute of Animal Breeding and Genetics, University of Goettingen, Albrecht-Thaer-Weg 3, 37075 Goettingen, Germany \\ ${ }^{2}$ Department of Endocrinology, University of Goettingen, Robert-Koch Strasse 40, 37075 Goettingen, Germany \\ (Correspondence should be addressed to M Komrakova; Email: komrakova@yahoo.com)
}

\begin{abstract}
The effect of daidzein (D), 4-methylbenzylidene camphor (4-MBC) or estradiol-17 $\beta$-benzoate $\left(\mathrm{E}_{2}\right)$ on muscle of osteoporotic rats during fracture healing was studied. After performing a metaphyseal tibia osteotomy in 96 osteoporotic 5-month-old female Sprague-Dawley rats, they received daily $50 \mathrm{mg} \mathrm{D,} 200 \mathrm{mg} 4-\mathrm{MBC}$ or $0.4 \mathrm{mg} \mathrm{E} 2$ per $\mathrm{kg}$ body weight, or soy free (SF) diet up to 36 and 72 days. Mitochondrial activity, fiber area, and capillary density were analyzed in M. gastrocnemius. Osseous callus bridging of fracture was observed in half of the rats after 36 days. By day 72 , fracture was healed in most of the animals. State 3 mitochondrial respiration significantly enhanced in $E_{2}$, 4-MBC and D groups versus SF after 36 days (30, 32 and 32 vs $23 \mathrm{pmol} \mathrm{O}_{2} / \mathrm{s}$ per $\mathrm{mg}$ ). It declined after 72 days,
\end{abstract}

however, in $\mathrm{E}_{2}$ group it was still at a higher level versus $\mathrm{SF}$ (25, 23 and 21 vs $20 \mathrm{pmol} \mathrm{O}_{2} / \mathrm{s}$ per $\mathrm{mg}$ ). Size of fast oxidative glycolytic (FOG) and fast glycolytic (FG) fibers, capillary density did not differ significantly between the groups, however, at day 36 an increase in D and 4-MBC groups was detectable. FOG diameter was $64,66,68$, and $58 \mu \mathrm{m}$ and $\mathrm{FG}$ diameter was $88,98,95$, and $89 \mu \mathrm{m}$ in SF, D, 4-MBC, and $\mathrm{E}_{2}$ groups. The ratio of capillaries to muscle fiber was $1 \cdot 1,1 \cdot 4$, $1 \cdot 3$, and $1 \cdot 1$ in SF, D, 4-MBC and $\mathrm{E}_{2}$ groups by day $36 . \mathrm{D}$ and 4-MBC react similar to estrogen thereby improving oxidative cell metabolism in severe osteoporotic rats. The level of mitochondrial activity was higher, though no significant morphological differences could be shown.

Journal of Endocrinology (2009) 201, 253-262

\section{Introduction}

Today it is still unclear which role the skeletal muscle plays in the main problem of osteoporosis, the traumatic event (fall), the osteoporotic fracture, and its healing process. A decline in estrogen production at menopause is associated with the failure to maintain muscle mass (Aloia et al. 1991). Loss in muscle strength appears to occur more rapidly than does the loss in bone mineral density after the onset of menopause (Marcus et al. 1994). Loss in muscle strength leads to a physical frailty, increasing risk of osteoporotic fracture, and may impair the fracture healing process to some extent.

Since bone and muscle are functionally linked, evaluation of muscle function in osteoporotic organisms is also important, particularly in situations where bone is adversely affected and the organisms are treated with osteoprotective substances to facilitate bone healing. Bone healing period is associated with an inactivity of the muscles that may cause their atrophy (Machida \& Booth 2004). It was demonstrated that ovarian hormone deficiency could play a role in the failure to recover muscle mass after a period of inactivity of the muscle (Sitnick et al. 2006). The presence of estrogen receptors in skeletal muscle indicates that skeletal muscle function is also regulated by estrogen (Piccone et al. 2004). Changes in hormone concentration have profound influence on muscle fibers. Ovariectomy in growing rat resulted in an increase of the diameter of all fiber types in muscles, whereas, estrogen replacement reduced the size of all types of fibers (Piccone et al. 2004). In muscles of mature female rodents, estrogen has been associated with modulation of muscle fiber types (Kadi et al. 2002, Feng et al. 2004), whereas, the crosssectional areas of all types of fibers were not affected by estrogen status (McClung et al. 2006, Moran et al. 2007). Moreover, estrogen has been reported to promote angiogenesis in skeletal muscles of estrogen deficient animals (Kyriakides et al. 2001).

Ovarian hormones have consistently been indicated in modulating mitochondrial function, such as ATP production, mitochondrial membrane potential, and calcium concentration (Wang et al. 2001, Nilsen \& Brinton 2003). 
The presence of mitochondrial estrogen receptors $\alpha$ and $\beta$ suggests that estrogens may act directly on the mitochondria (Yang et al. 2004, Stirone et al. 2005). Given the importance of mitochondria in basic cellular functions as well as the critical role of mitochondrial dysfunction in the development of various diseases (e.g. Stirone et al. 2005) an important question is whether osteoprotection through estrogenic substances also exerts effects on the mitochondria in muscle.

Post-menopausal estrogen replacement therapy (ERT) was often recommended for prevention and treatment of osteoporosis (Glazier \& Bowman 2001) as well as for maintaining muscle strength and mass (Phillips et al. 1993, Sorensen et al. 2001). However, ERT is associated with potential side effects on reproductive tissues, such as breast cancer and refused as being unnatural by women (Glazier \& Bowman 2001). This has driven a search for substances that produce only beneficial effects without undesirable effects, especially on the reproductive organs.

Recently, much attention has been focused on phytoestrogens, especially isoflavones, as a potential safe alternative for pharmaceutical ERT (Glazier \& Bowman 2001). Soy and soy products are the richest source of dietary isoflavones in humans. Daidzein (D) is the prevalent isoflavone in soy and has attracted the most clinical interest because of its weak estrogenic effect when consumed by animals or humans (e.g. Picherit et al. 2000). D was demonstrated to prevent bone loss without any adverse effects on the uterus in the ovariectomized (Ovx) rat model of post-menopausal osteoporosis (Picherit et al. 2000). Nowadays, phytoestrogens containing $\mathrm{D}$ are commercially available as dietary supplements.

Several u.v. filters frequently used in cosmetics represent new classes of endocrine active chemicals that have been found to have estrogenic effect if applied in animals (Schlumpf et al. 2001, 2008). 4-Methylbenzylidene camphor (4-MBC) exhibited the highest estrogenic activity in vivo in the group of u.v. filters studied (Schlumpf et al. 2001). It has been shown that 4-MBC prevented bone loss and exerted a very weak estrogenic effect on the uterus and the vagina after a 3-month treatment of Ovx rats (Seidlová-Wuttke et al. 2006).

Whereas the beneficial effect of D or 4-MBC treatment on osteoporotic bones has been reported (Picherit et al. 2000, Seidlová-Wuttke et al. 2006), the effect on skeletal muscle of estrogen deficient organisms has not been studied so far. Therefore, the aim of the present study was to investigate the effect of D, 4-MBC and estrogen on mitochondrial function and structure of the M. gastrocnemius (MG) in osteoporotic rat during fracture-healing period.

\section{Materials and Methods}

\section{Animals and treatments}

Ninety six 3-month old Sprague-Dawley rats (Harlan Winkelmann, Borchen, Germany) were bilaterally Ovx under i.p. ketamine (Medistar, Holzwickede, Germany) and xylazine (Riemser, Greifswald-Insel Riems, Germany) anesthesia (40 mg and $10 \mathrm{mg}$ per $\mathrm{kg}$ of body weight (BW) respectively) and then randomly assigned into four groups, each consisting of 24 rats. Rats were housed 3-4 in standard cages under $12 \mathrm{~h}$ darkness: $12 \mathrm{~h}$ light regimes at a constant temperature of $22 \pm 1{ }^{\circ} \mathrm{C}$. Rats received soy free pelleted diet containing potato protein. Soy proteins were substituted by potato proteins to eliminate an estrogenic effect of isoflavones presented in soy. After 8 weeks, when osteoporosis was established (Kalu 1991), a metaphyseal osteotomy and T-plate fixation of the tibiae was done under ketamine/xylazine anesthesia as described previously (Stuermer et al. 2008). Along with anesthesia, rats received s.c. $5 \mathrm{mg}$ Decentan (Merck) and $4 \mathrm{mg}$ Rimadyl (Pfizer, Karlsruhe, Germany) per kg of BW respectively. Rimadyl was given two times per day during two postoperative days.

After operation (day 0), animals were fed with special diets (Ssniff special diet GmbH, Soest, Germany). Group 1 received soy free (SF) diet. Group 2 was given a diet supplemented with $5 \mathrm{~g}$ 4-MBC per $\mathrm{kg}$ of diet. Group 3 received diet supplemented with $1 \mathrm{~g}$ D (purity of 98\%, Changzhou Dahua Imp. and Exp. (Group) Corp. Ltd, Jiangsu, China) per kg of diet and Group 4 received a diet containing $10 \mathrm{mg}$ estradiol$17 \beta$-benzoate $\left(\mathrm{E}_{2} ;\right.$ Merck) per kg.

The daily intake was calculated by weekly weighing of food. All animals had free access to food and water throughout the experiment. Animals were weighed on the day of ovariectomy and weekly during 72 days of administration of supplemented diet. A daily dosage of 4-MBC averaged $200 \mathrm{mg}$ per $\mathrm{kg} \mathrm{BW}$ (Schlumpf et al. 2001). Daily dosages of $\mathrm{D}$ and estrogen were on average $50 \mathrm{mg}$ and $0.4 \mathrm{mg}$ per $\mathrm{kg} \mathrm{BW}$ respectively (Vortherms 2006). The doses of 4-MBC and D were selected on the basis of previous studies showing beneficial effects on osteoporotic bones (Picherit et al. 2000, Seidlová-Wuttke et al. 2006). The daily intake of $0.4 \mathrm{mg}$ estrogen per $\mathrm{kg} \mathrm{BW}$ results in serum estrogen concentration of about $40 \mathrm{pg} / \mathrm{ml}$ (Vortherms 2006). This is within the physiological range reported for healthy female rat (Krinke 2000).

Four rats died during the study (one each of $\mathrm{SF}$ and $\mathrm{E}_{2}$ groups day 36 and two of the $\mathrm{E}_{2}$ group day 72 ). A reduction in physical activity of the rats was observed subjectively during the first two days after osteotomy.

After 36 and 72 days of supplemented feeding, 12 animals of each group were decapitated under carbon dioxide anesthesia. Immediately, MG was extracted randomized from either the left or right limb of the rats. The MG was chosen because of its location at a fracture site and its large size that enabled us to collect samples from the same (middle) part of the muscle for both mitochondrial and histological analyses. From the middle part of the $\mathrm{MG}$ a piece of muscle, about $80 \mathrm{mg}$, was immersed in ice cold storage medium, pH 7·1 (15 mM phosphocreatine, $49 \mathrm{mM}$ KMES, $20 \mathrm{mM}$ taurine, $20 \mathrm{mM}$ imidazole, $5.2 \mathrm{mM}$ ATP, $9.5 \mathrm{mM}$ 
$\mathrm{MgCl}_{2} \times 6 \mathrm{H}_{2} \mathrm{O}, 3 \mathrm{mM} \mathrm{KH}_{2} \mathrm{PO}_{4}, 0.5 \mathrm{mM}$ dithiothreitol (DTT), $1.9 \mathrm{mM}$ Ca-K-EGTA water solution $(3.804 \%$ EGTA, $1 \cdot 122 \% \mathrm{KOH}, 1 \% \mathrm{CaCO}_{3}$ dissolved at $80{ }^{\circ} \mathrm{C}, \mathrm{pH}$ adjusted to $7 \cdot 0$ with $\mathrm{KOH}$ ), and $8 \cdot 1 \mathrm{mM} \mathrm{K}$-EGTA solution, same as Ca-K-EGTA solution without $\mathrm{CaCO}_{3}$ ) for up to $1 \mathrm{~h}$ before respirometric measurements were performed. A block of muscle $\left(1 \times 1 \times 1 \mathrm{~cm}^{3}\right)$ was removed from the same region of the $M G$, frozen directly in liquid nitrogen after coating it with talcum (Moline \& Glenner 1964) and stored at $-80^{\circ} \mathrm{C}$ until analyses of muscle fibers and capillaries. Uterine wet weight was recorded. Tibia randomized from either right or left limb was dissected free of soft tissues and after extraction of plate and screws were stored at $-20{ }^{\circ} \mathrm{C}$ until histomorphological analyses.

The animal study protocol was approved by the local regional government and conformed to German animal protection laws (permission from 12/05/03, Az: 509.42502/ 01-53.03 District Government of Braunschweig).

All chemicals were obtained from Sigma-Aldrich Chemie $\mathrm{GmbH}$, unless otherwise indicated.

\section{Respirometric measurements}

Muscle samples were prepared as described previously (Trumbeckaite et al. 2001) with some modifications. Ten to $20 \mathrm{mg}$ samples were carefully dissected and permeabilized for $20 \mathrm{~min}$ in $1 \mathrm{ml}$ storage medium (stated above) supplemented with $50 \mu \mathrm{g}$ saponin per $\mathrm{ml}$. Permeabilized muscle fibers were washed in three 5-min changes of incubation medium ( $\mathrm{pH} 7 \cdot 4$ ) consisting of $75 \mathrm{mM}$ mannitol, $25 \mathrm{mM}$ sucrose, $100 \mathrm{mM} \mathrm{KCl,} 0.5 \mathrm{mM}$ EDTA, $20 \mathrm{mM}$ Tris- $\mathrm{HCl}, \quad 5 \mathrm{mM} \quad \mathrm{MgCl}_{2} \times 6 \mathrm{H}_{2} \mathrm{O}, \quad 10 \mathrm{mM}$ $\mathrm{KH}_{2} \mathrm{PO}_{4}, 0.5 \mathrm{mM} \mathrm{DTT}$, and $1 \mathrm{mg}$ per $\mathrm{ml}$ fatty acid free BSA. All procedures were performed on ice.

Respirometric measurements were made using an Oroboros Oxygraph (Oroboros, Innsbruck, Austria), a two chamber respirometer with integrated electromagnetic stirrers. Bundles of fibers $(3-7 \mathrm{mg})$ were carefully dried on a filter paper and added to the oxygraph chambers. The measurements were performed at $30{ }^{\circ} \mathrm{C}$ in $2 \cdot 1 \mathrm{ml}$ incubation medium using the added substrates pyruvate $(9.5 \mathrm{mM})$ and malate $(1.9 \mathrm{mM})$. The weight specific oxygen consumption rate (pmol $\mathrm{O}_{2} / \mathrm{s}$ per $1 \mathrm{mg}$ sample weight) was calculated as the time derivative of the oxygen concentration (DatLab 4.0 analysis software, Oroboros). The rate of state 3 respiration was determined following the addition of $5 \mathrm{mM}$ ADP. The effect of ADP was recorded and state 4 respiration was initiated by the addition of $26 \mu \mathrm{M}$ carboxyatractyloside (Calbiochem, Darmstadt, Germany; EMD Chemicals Inc., Darmstadt, Germany; Merck), an inhibitor of the ADP/ATP translocation. Physiological respiratory activity of mitochondria was estimated by calculating the respiratory control ratio (RCR) defined as ADP-stimulated (state 3) respiration rate divided by the resting (state 4 ) respiration rate (Renner $\&$ Gnaiger 2003). At least five replications per treatment group were done.
Analyses of muscle fibers

Serial cross sections of $12 \mu \mathrm{m}$ were cut in a cryostat at $-20{ }^{\circ} \mathrm{C}$ and mounted on glass slides. Sections were fixed for $1 \mathrm{~min}$ in $1 \%$ (v/v) paraformaldehyde solution ( $\mathrm{pH} \mathrm{6.6)}$ containing $1 \%(\mathrm{w} / \mathrm{v}) \mathrm{CaCl}_{2}$ and $6 \%(\mathrm{w} / \mathrm{v})$ sucrose (Meijer 1970) followed by two 5-min washing in distilled water. A modified procedure of Horák (1983) was used to stain the sections. Sections were subjected to the following consecutive actions: a) incubation in Diaphorase solution consisting

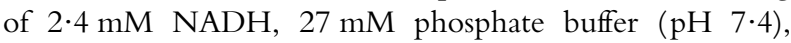
$0.4 \mathrm{mM}$ nitro blue tetrazolium chloride at $37^{\circ} \mathrm{C}$ under humidified atmosphere for $60 \mathrm{~min}$; b) washing in distilled water for $15 \mathrm{~min}$; c) pre-incubation in $18 \mathrm{mM} \mathrm{CaCl}_{2}$ with addition of $0 \cdot 4 \%(\mathrm{v} / \mathrm{v})$ glacial acetic acid, $\mathrm{pH} 4 \cdot 2$ for $15 \mathrm{~min}$; d) washing in $100 \mathrm{mM}$ Tris buffer (Tris (hydroxymethyl) aminomethane), $\mathrm{pH} 7 \cdot 8$ containing $18 \mathrm{mM}$ $\mathrm{CaCl}_{2}$ for 2 min; e) ATPase incubation ( $\mathrm{pH} 9 \cdot 4$ ) consisting of $0.1 \mathrm{M}$ glycine ( $\mathrm{pH} 9 \cdot 4$ ), $18 \mathrm{mM} \mathrm{CaCl}_{2}, 48 \cdot 8 \mathrm{mM} \mathrm{KCl}$, $2.8 \mathrm{mM} \mathrm{ATP}$ at $37^{\circ} \mathrm{C}$ for $30 \mathrm{~min}$; f) washing in three $30-\mathrm{s}$ changes of $68 \mathrm{mM} \mathrm{CaCl}_{2}$; g) treatment in $84 \mathrm{mM}$ cobalt chloride for $3 \mathrm{~min}$; h) washing in three 30-s changes of distilled water; i) incubation in $0.08 \%(\mathrm{v} / \mathrm{v})$ ammonium sulfide solution for $3 \mathrm{~min} ; \mathrm{j}$ ) rinsing in running water for $10 \mathrm{~min}$ followed by immersing in distilled water for $5 \mathrm{~min}$. Thereafter, samples were air-dried and fixed with cover slips using Canadian balsam. Representative sections were used for final measurements of fast-twitch oxidative glycolytic (FOG) and fast-twitch glycolytic (FG) fibers classified according to Peter et al. (1972). Slow-twitch oxidative (SO) fibers were rarely represented among the samples, therefore were not included in the analyses. The fiber cross sectional area and diameter of each histochemical fiber type were measured after transfer of representative section of the muscle with the aid of a digital camera (DVC 1310 C, DVC Company, Maidenhead, UK) and a microscope (Eclipse E 600 , Nikon, Tokyo, Japan) at a magnification of $\times 10$ using a computerized image analysis program (Lucia G, Laboratory Imaging, Version 4.82). The outline of the fiber contour was manually defined on a digital image. At least 50 FOG and FG fibers in each rat muscle were typed and measured. Ten animals per treatment group were analyzed.

\section{Analyses of muscle capillaries}

Periodic acid-Schiff (PAS) staining method (Andersen 1975) was applied with some modifications to stain the blood capillaries. Serial cross sections of $12 \mu \mathrm{m}$ were fixed for $1 \mathrm{~h}$ in ethanol/chloroform/glacial acid (16:3:1) at $4{ }^{\circ} \mathrm{C}$ followed by $10-\mathrm{min}$ fixation at room temperature and subsequent 10 changes of distilled water. Thereafter, sections were treated with $0 \cdot 3 \%(\mathrm{w} / \mathrm{v})$ water solution of $\boldsymbol{\alpha}$-amylase (from porcine pancreas) for $25 \mathrm{~min}$ at $37^{\circ} \mathrm{C}$, and after ten changes of distilled water, with $1 \%(\mathrm{w} / \mathrm{v})$ periodic acid for $30 \mathrm{~min}$. Washing in ten changes of distilled water was repeated and the sections were placed in Schiff's Reagent solution 
(Roth, Karlsruhe, Germany) for $35 \mathrm{~min}$ followed by treatment with $10 \%(\mathrm{w} / \mathrm{v})$ potassium sulfite/1 $\mathrm{N} \mathrm{HCl} /$ water $(1: 1: 20)$ for $30 \mathrm{~min}$. Finally, sections were rinsed in running water for $10 \mathrm{~min}$ followed by immersing in distilled water for 5 min. Air-dried samples were fixed with cover slips using Canadian balsam. Capillaries and fibers found in five randomly selected fields $\left(1 \mathrm{~mm}^{2}\right.$ each $)$ from the muscle section were counted at a magnification of $\times 10$ (microscope Eclipse E 600) using a digital camera (DVC 1310 C, DVC Company) and image analysis program (Lucia G, Laboratory Imaging, Version 4.82). The ratio of capillaries to muscle fiber was taken in the analyses. At least five replications per treatment group were done.

\section{Analyses of bone healing}

The labeling of new bone formation during fracture healing was performed in vivo according to Rahn (1976) using fluorescence dyes xylenol orange (XO; $90 \mathrm{mg} / \mathrm{kg} \mathrm{BW})$, calcein green (CG; $10 \mathrm{mg} / \mathrm{kg} \mathrm{BW})$, alizarin complexone (AC; $30 \mathrm{mg} / \mathrm{kg} \mathrm{BW}$ ) and tetracycline (T; $25 \mathrm{mg} / \mathrm{kg} \mathrm{BW}$ ) injected subcutaneously. The dyes were applied on day 13 (XO), on day 18 (CG), on days 22 and 24 (AC), and on day $36(\mathrm{~T})$ in animals treated up to 36 days. Rats kept for up to 72 days received $\mathrm{XO}$ on day 36, CG on day 47, AC on days 56 and 59 , and TC on day 72. Tibia was thawed and subjected to the sequential ascending concentrations of ethanol followed by embedding in methylmethacrylate (Merck). Longitudinal sections $150 \mu \mathrm{m}$ thick were cut at right angles to the plate position in the center of the specimens using Leica SP 1600 diamond saw microtome (Leica Instruments $\mathrm{GmbH}$, Nussloch, Germany). Three representative sections from the center of each tibia were mounted on glass slides with stable medium (Eukitt, O Kindler GmbH, Freiburg, Germany) for fluorescence microscopy. The mounted sections were digitalized using Leica MZ75 microscope equipped with Leica DC 200 digital camera (Bensheim, Germany) and analyzed qualitatively. The osteotomy gap was divided into three regions of interest: 1) plate side; 2) opposite side; 3) the medullar part of the tibia. Time of the earliest callus and new bone bridging of fracture gap was determined by analyses of fluorochrome labeling according to the regions of interest.

\section{Statistical analyses}

Statistical analyses were conducted using SAS program (Version 8). ANOVA ( $F$-test, $P<0 \cdot 05)$ were applied to reveal the impact of two fixed effects (diets, duration of their administration) on the food intake and weight of the animals. Analyses of covariate with weight of the rats as a covariate ( $F$-test, $P<0 \cdot 05)$ was used to study the effects of 'diets' and 'duration' on mitochondrial respiration, muscle fibers, and capillaries. The weight of the animals had no significant effect on the respective variables (F-test, $P>0 \cdot 05)$. Differences between individual means were estimated using Schéffe-test $(P<0 \cdot 05)$.

\section{Results}

\section{Food intake}

Food intake significantly increased during the first 22 days of feeding among the groups, but during further feeding changes were not significant (Fig. 1).

Average food intake in groups SF and D was higher (15 g/rat per day in both groups) compared with that in 4-MBC and $\mathrm{E}_{2}$ groups (14 and $13 \mathrm{~g} /$ rat per day respectively). Rats of the 4-MBC group consumed on average significantly more than those in $\mathrm{E}_{2}$ group, however, it was less $(P<0 \cdot 05)$ than that in SF and D groups. The differences are shown in Fig. 1 in detail.

\section{Body weight}

$\mathrm{BW}$ of the rats increased significantly among the groups (Fig. 2) after ovariectomy. During the first 2 weeks after osteotomy and supplemented feeding, the BW significantly decreased in all groups. Thereafter, it continuously rose approaching in groups SF, D and 4-MBC the level measured at the date of osteotomy (Fig. 2). In group $\mathrm{E}_{2}$, it remained at a lower level throughout the experiment.

The BW was significantly higher in SF group than that in group 4-MBC and $\mathrm{E}_{2}$ from the second week onward (Fig. 2). In group $\mathrm{D}$, the $\mathrm{BW}$ was lower compared with that in SF group during experiment, however, the differences were not significant. The lowest $(P<0 \cdot 05) \mathrm{BW}$ was observed in group $\mathrm{E}_{2}$. The $\mathrm{BW}$ of the group $\mathrm{D}$ and $4-\mathrm{MBC}$ differed not significantly (Fig. 2).

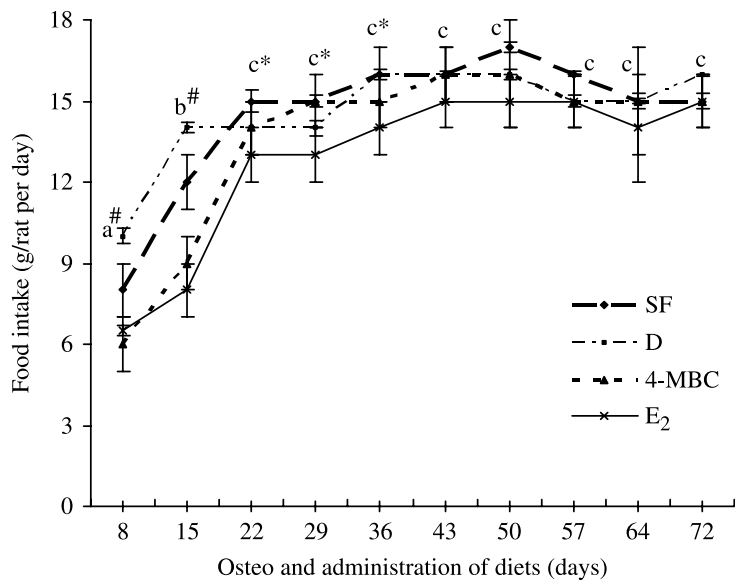

Figure 1 Food intake (g/rat per day) of osteoporotic rats subjected after osteotomy of tibia (day 0, osteo) either to soy free diet (SF) or daidzein $(D), 4-M B C$, estradiol-17 $\beta$-benzoate $\left(E_{2}\right)$ supplemented diet during tibia healing for up to 72 days. Data are presented as means and S.E.M. Between days means with different letters differ $\left(P<0 \cdot 05\right.$, Scheffé-test). ${ }^{*} \mathrm{SF}$ versus $\mathrm{E}_{2}$ differ, ${ }^{\#} \mathrm{SF}$ versus $4-\mathrm{MBC}$ and $\mathrm{E}_{2}, \mathrm{D}$ versus $4-\mathrm{MBC}$ and $\mathrm{E}_{2}$ differ $(P<0 \cdot 05$, Scheffé-test). 


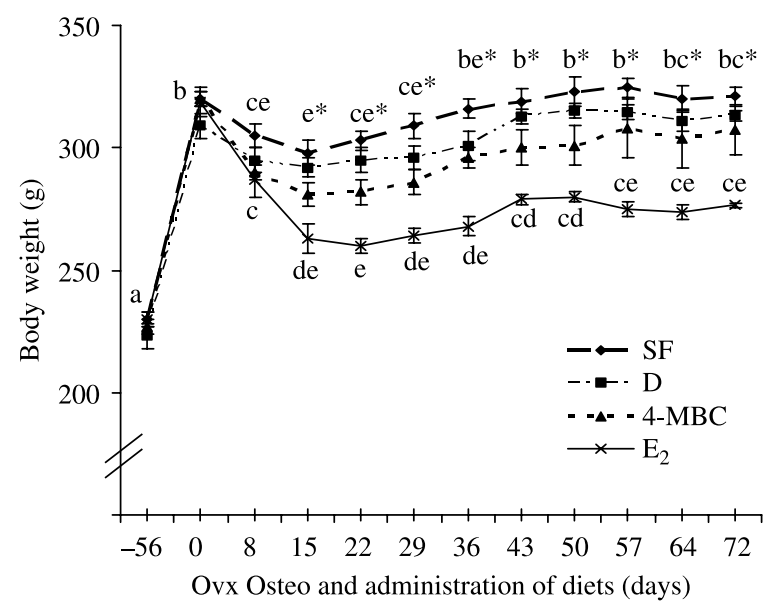

Figure 2 Body weight of the rats (g) ovariectomized at day 56 (Ovx) subjected after osteotomy of tibia (day 0 , osteo) either to soy free (SF) diet or diet supplemented with daidzein (D), 4-MBC, estradiol$17 \beta$-benzoate $\left(E_{2}\right)$ for up to 72 days. Data are presented as means and S.E.M. Between days, means with different letters differ $(P<0 \cdot 05$, Scheffé-test), showed combined for groups SF, D, and 4-MBC. *SF versus $4-\mathrm{MBC}$ and $\mathrm{E}_{2}, 4 \mathrm{MBC}$ versus $\mathrm{E}_{2}$ differ $(P<0 \cdot 05$, Scheffé-test).

\section{Uterus weight}

The uterus weight significantly differed between the treatment groups during experiment. In Ovx rats treated with estrogen, the mean uterus weight was significantly higher compared with that observed in Ovx rats in groups SF, $\mathrm{D}$ and 4-MBC (585 $\mathrm{mg}$ versus 233, 217 and $239 \mathrm{mg}$ respectively). The differences in uterus weight measured in $\mathrm{SF}, \mathrm{D}$ and $4-\mathrm{MBC}$ groups were negligible $(P>0 \cdot 05)$. Average S.E.M. was 22 .

\section{Respirometric measurements}

State 3 and state 4 respiration significantly declined between day 36 and 72 of supplemented feeding. RCR ratio tended to decline with the time as well (Table 1). In groups $\mathrm{D}$ and 4-MBC, state 3 respiration decreased significantly from 32 to 21 or 23 pmol $\mathrm{O}_{2} / \mathrm{s}$ per mg sample weight respectively, reaching the level observed in SF group $\left(20 \mathrm{pmol} \mathrm{O}_{2} / \mathrm{s}\right.$ per mg sample weight) that remained unchanged. In group D state 4 respiration decreased significantly with prolonged treatment from 6 to $3 \mathrm{pmol} \mathrm{O}_{2} / \mathrm{s}$ per $\mathrm{mg}$ sample weight respectively.

Between the groups, the significant difference was revealed only in state 3 respiration rate (Table 1). After 36 days, state 3 respiration rate was significantly higher in animals fed with supplemented diet compared with those fed with unsupplemented diet (SF). As the bone healing was completed at day 72 , only in group $\mathrm{E}_{2}$ did state 3 respiration remain on a higher level (Table 1).

\section{Analyses of muscle fibers}

The cross sectional areas and diameter of FG and FOG fibers did not change $(P>0 \cdot 05)$ during the period of supplemented feeding among the groups (Table 2). Between the groups, the differences in the cross-sectional area and the diameter of both fiber types were insignificant $(P>0 \cdot 05)$. After 36 days of treatment period, cross sectional area and diameter of fibers were slightly, though not significantly enlarged in groups D and 4-MBC compared with others (Table 2). After 72 days, it was less pronounced. No sign of degeneration was detected in muscle fibers during preparation of samples.

\section{Analyses of muscle capillaries}

The density of capillaries did not significantly change between the treatment groups (Fig. 3). After 36 days, the ratio of capillaries to muscle fiber was slightly, though not significantly enhanced in groups D and 4-MBC (1.4 and 1.3) compared with that in groups $\mathrm{SF}$ and $\mathrm{E}_{2}$ that was $1 \cdot 1$. During

Table 1 Mitochondrial respiration rates (pmol $\mathrm{O}_{2} / \mathrm{s}$ per $\mathrm{mg}$ sample weight) in saponin-permeabilized fibers of gastrocnemius muscle of osteoporotic rats fed during tibia healing either with soy free (SF), daidzein (D), 4-methylbenzylidene camphor (4-MBC) or estradiol-17ßbenzoate $\left(E_{2}\right)$ supplemented diet up to 36 and 72 days measured with substrates: $9.5 \mathrm{mM}$ pyruvate and 1.9 mM malate in the presence of $5 \mathrm{mM}$ ATP (state 3 ) and $26 \mu \mathrm{M}$ carboxyatractyloside (state 4)

\begin{tabular}{|c|c|c|c|c|c|c|c|c|}
\hline & & & State 3 & & State 4 & & RCR & \\
\hline & Diets & No & Mean & S.E.M. & Mean & S.E.M. & Mean & S.E.M. \\
\hline Day & & & & & & & & \\
\hline 36 & SF & 5 & $23^{A x}$ & 3 & $3^{\mathrm{A}}$ & 1 & 10 & 3 \\
\hline & $\mathrm{D}$ & 8 & $32^{\mathrm{Ay}}$ & 3 & $6^{\mathrm{A}}$ & 1 & 8 & 2 \\
\hline & 4-MBC & 5 & $32^{\mathrm{Ay}}$ & 5 & $5^{\mathrm{A}}$ & 1 & 9 & 3 \\
\hline & $E_{2}$ & 8 & $30^{A y}$ & 1 & $5^{\mathrm{A}}$ & 1 & 9 & 3 \\
\hline 72 & $\mathrm{SF}$ & 10 & $20^{A x}$ & 2 & $3^{\mathrm{A}}$ & $0 \cdot 4$ & 6 & 1 \\
\hline & $\mathrm{D}$ & 8 & $21^{\text {Bxy }}$ & 1 & $3^{\text {B }}$ & 1 & 7 & 1 \\
\hline & $4-M B C$ & 9 & $23^{B x y}$ & 2 & $4^{\mathrm{A}}$ & $0 \cdot 3$ & 7 & 1 \\
\hline & $E_{2}$ & 9 & $25^{A y}$ & 3 & $4^{\mathrm{A}}$ & 1 & 7 & 1 \\
\hline
\end{tabular}

RCR: state 3 divided by state 4 . At least five replications per treatment were conducted. ${ }^{x y}$ Between diets means with different letters differ on day 36 or 72 $\left(P<0 \cdot 05\right.$, Schéffe-test). ${ }^{\mathrm{AB}}$ Means of the diet with different letters differ on 36 vs $72 \mathrm{~d}(P<0 \cdot 05$, Schéffe-test). 
Table 2 Cross sectional area $\left(\mu \mathrm{m}^{2}\right)$ and diameter $(\mu \mathrm{m})$ of fast glycolytic (FG) and fast oxidative glycolytic (FOG) fibers in gastrocnemius muscle of osteoporotic rats exposed during tibia healing period either to soy free (SF) diet or daidzein (D), 4-methylbenzylidene camphor (4-MBC), estradiol-17ß-benzoate $\left(E_{2}\right)$ supplemented diet up to 36 or 72 days. Treatments were conducted with 10 replications

\begin{tabular}{|c|c|c|c|c|c|c|c|c|c|}
\hline & & Cross & al area, FG & Diame & & Cross s & al area, FOG & Diame & \\
\hline & Diets & Mean & S.E.M. & Mean & S.E.M. & Mean & S.E.M. & Mean & S.E.M. \\
\hline Day & & & & & & & & & \\
\hline 36 & SF & 6204 & 409 & 88 & 3 & 3277 & 333 & 64 & 3 \\
\hline & $\mathrm{D}$ & 7685 & 487 & 98 & 3 & 3548 & 287 & 66 & 3 \\
\hline & 4-MBC & 7120 & 218 & 95 & 2 & 3691 & 259 & 68 & 2 \\
\hline & $\mathrm{E}_{2}$ & 6367 & 728 & 89 & 5 & 2759 & 344 & 58 & 4 \\
\hline 72 & SF & 6969 & 594 & 93 & 4 & 2978 & 274 & 61 & 3 \\
\hline & $\mathrm{D}$ & 6794 & 530 & 92 & 4 & 3170 & 185 & 63 & 2 \\
\hline & 4-MBC & 6471 & 568 & 90 & 4 & 2806 & 216 & 59 & 2 \\
\hline & $\mathrm{E}_{2}$ & 6636 & 426 & 91 & 3 & 3100 & 244 & 62 & 3 \\
\hline
\end{tabular}

The differences were not significant $(P>0 \cdot 05, F$-test $)$.

further treatment (day 72$)$, this was not detectable $(1 \cdot 2,1 \cdot 1$, $1 \cdot 2$, and $1 \cdot 0$ in groups $\mathrm{SF}, \mathrm{D}, 4-\mathrm{MBC}$ and $\mathrm{E}_{2}$ respectively).

\section{Analyses of bone healing}

Qualitative analyses of fracture healing showed that after 36 days post-fracture, bone healing was not complete and fracture gap could be clearly observed in all groups. Callus bridging was observed in about half of the animals (Table 3 ). The bridging occurred during the fourth week of healing predominating endosteally and at the side opposite to the plate. At the side of the plate, less callus bridging was observed. In animals of SF, 4-MBC, and D groups prevailed periosteal callus bridging formed at the side opposite to the plate, whereas, in estrogen treated animals endosteal bridging was superior (Table 3). High-trabecular connectivity was observed among the groups.

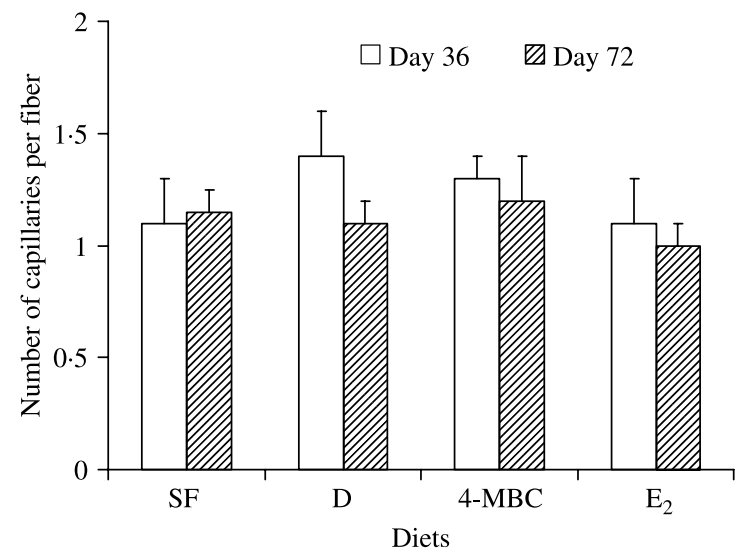

Figure 3 Number of capillaries per muscle fiber measured in gastrocnemius muscle of osteoporotic rats exposed during tibia healing period either to soy free (SF) diet or daidzein (D), 4-MBC, estradiol-17 $\beta$-benzoate $\left(E_{2}\right)$ supplemented diet up to 36 and 72 days. Data are presented as means and S.E.M. The differences were not significant $(P>0 \cdot 05, F$-test $)$.
By day 72 , the fracture gap was united in $92 \%$ of animals in both SF and D groups. In groups 4-MBC and $\mathrm{E}_{2}$, united fracture gap was observed in 67 and 60\% of animals respectively (Table 3). Periosteal callus appeared to be homogenously filled with newly formed bone, whereas original cortical bones tended to resorb. New bone bridged the fracture gap during the sixth week of the healing. Endosteal callus was partially or completely resorbed. The SF, 4-MBC, and D groups showed poor-trabecular continuity.

\section{Discussion}

Mature Ovx rats are often used as an animal model for studying the effect of post-menopausal ovarian hormone deficiency on various organs and systems (Kalu 1991). The intent of our study was to evaluate the therapeutical effect of phytoestrogen D, u.v. filter 4-MBC and estrogen on the structure and mitochondrial function of skeletal muscles of severe osteoporotic rats during bone fracture healing period. We tried to mimic clinical situation the best, when a typical patient (female) with osteoporotic fracture, before being traumatized, suffers for years from post-menopausal changes in muscle and bone and receives no fracture preventive treatment (Haeussler et al. 2007). Therefore, a metaphyseal osteotomy of tibia was performed after severe osteoporosis had been established (Wronski et al. 1985, Stuermer et al. 2008) and the animals received the substances orally to facilitate bone healing. Finally, the comparisons were made with osteoporotic rats either untreated serving as an osteoporotic control or properly treated with estrogen to meet the goal of the present experiment.

\section{Analyses of muscle}

In the present study, we showed that D, 4-MBC as well as estrogen treatment beneficially affected mitochondrial activity in MG of osteoporotic rat after 36 days of their administration (31 vs $23 \mathrm{pmol} \mathrm{O}_{2}$ /s per mg sample weight in osteoporotic 
Table 3 Qualitative analyses of tibia fracture healing in osteoporotic rats exposed either to soy free (SF), daidzein (D), 4-methylbenzylidene camphor $(4-\mathrm{MBC})$ or estradiol-17 $\beta$-benzoate $\left(\mathrm{E}_{2}\right)$ supplemented diet up to 36 and 72 days post-fracture determined using fluorochromelabeled sections according to the plate side, opposite side, and endosteally

\section{Treatment groups}

Histological event

\begin{tabular}{llll}
\hline $\mathrm{SF}$ & $\mathrm{D}$ & $4-\mathrm{MBC}$ & $\mathrm{E}_{2}$
\end{tabular}

Days

36 Total number of animals

Osseous callus bridging (number of animals)

Periosteal bridging plate side

Periosteal bridging opposite side

Endosteal bridging

Osseous callus bridging (days after fracture)

Periosteal bridging plate side

Periosteal bridging opposite side

Endosteal bridging

$72^{\mathrm{a}} \quad$ Total number of animals

United fracture gap (number of animals)

Periosteal plate side

Periosteal opposite side

Endosteal

$\begin{array}{rr} & \\ 11 & \\ 6 & 12 \\ 3 & 9 \\ 6 & 4 \\ 3 & 9 \\ 27 & 8 \\ 28 & 25 \\ 25 & 26 \\ 27 & 25 \\ 12 & 23 \\ 11 & 12 \\ 9 & 11 \\ 11 & 8 \\ 6 & 9 \\ & 6\end{array}$

$4-\mathrm{MBC}$

$E_{2}$

${ }^{a} \mathrm{New}$-bone bridging was on average on day 47 of healing in all treatment groups.

group respectively). It was assumed that osteotomy of tibia may result in an activation of regenerative mechanisms increasing vascularization around the injury place after 36 days and decreasing it as the bone healing is completed at day 72. According to Walsh et al. (1997), bone fracture is able to completely heal within 6 weeks in osteoporotic rats. Indeed, in the animal model used in the present study, fractured bones were healed in most of the animals by day 72 . Although estrogen has been shown to stimulate angiogenesis in skeletal muscles (Kyriakides et al. 2001), we observed a slight increase in capillary density in D and 4-MBC treated rats, but not in the estrogen supplemented animals after 36 days of fracture healing. On the other hand, the estrogenic effect of the substances may facilitate the animals to restore their physical activity more rapidly. A drop in physical activity in Ovx rats has been observed (Wade 1972, Kadi et al. 2002), whereas, estrogen substitution is associated with a normalization of the level of physical activity (Kadi et al. 2002). The maintenance of state 3 respiration rate in the estrogen group at a significantly higher level throughout the experiment suggests that this was caused by action of estrogen on mitochondrial function via the mitochondrial estrogen receptors. The presence of mitochondrial estrogen receptors $\alpha$ and $\beta$ has been reported suggesting that estrogens may act directly on the mitochondria (Yang et al. 2004, Stirone et al. 2005). Stirone et al. (2005) showed that estrogen is able to modulate mitochondrial function in cerebral blood vessels that resulted in a greater energy production capacity. They reported that estrogen could act through both mitochondrial and nuclear genomes involving multiple mechanisms to enhance mitochondrial function. In skeletal muscles of rat, ovariectomy decreased activity of mitochondrial fat oxidative enzymes, while maximal activity of these enzymes was restored by estrogen treatment (Campbell \& Febbraio 2001). D and 4-MBC have been reported to have binding affinity to estrogen receptors acting as weak estrogens (Picherit et al. 2000, Mueller et al. 2003, Schlumpf et al. 2004). Thus, it is possible that D and 4-MBC react similar to estrogen on mitochondria improving oxidative cell metabolism of the animals. A slightly increased blood supply to the muscle and a more rapid return to the normal physical activity in the D, 4-MBC, and estrogen treated animals might have enhanced the mitochondrial respiration rate at day 36 . Further investigations are under progress to elucidate these assumptions.

The combination of NADH enzyme for aerobic oxidative metabolism reaction and myofibrillary ATPase histochemistry showed that the diameter and cross-sectional area of FOG and FG fibers were unaltered irrespective of food supplements or duration of their administration in mature female rat. Our results are in agreement with Moran et al. (2007) who found, that the cross-sectional areas of all fiber types were not affected by estrogen status in mature female rodents. We rarely observed slow oxidative fibers across the samples, as also found in MG by Armstrong \& Phelps (1984).

$\mathrm{D}$ and 4-MBC affected slightly, though not significantly, the muscle fibers, enhancing their size at the early stage of fracture healing (day 36 after osteotomy). During aging up to 7 months (day 72 after osteotomy), these changes could not be detected. A general body growth including muscle growth may also contribute to these changes. According to Berg \& Harmison (1957) linear growth of Sprague-Dawley rat was rapid until 170 days and then declined markedly. The difference in the BW of rats found between the treatment groups seems to have occurred independently of changes in muscle fibers. Significant changes in physical activity and 
metabolism in Ovx rats, discussed above are responsible for the increase in adipose tissues and the BW, consequently. In other studies, increased wet muscle mass in Ovx versus estrogen replaced adult female rodents was explained by an extracellular fluid accumulation because the cross-sectional area of all fiber types was not affected by estrogen status (McClung et al. 2006, Moran et al. 2007).

In a previous study, it was stated that estrogen replacement in Ovx rats benefited atrophied muscle recovery from disuse atrophy (Kawano et al. 1997). McClung et al. (2006) reported that a cross-sectional area of muscle fibers was able to fully recover after 28 days, regardless of the rats were intact, Ovx or estrogen replaced. Our results corroborate these findings displaying no significant differences in the size of muscle fibers after 36 and 72 days of bone-healing period.

\section{Animal model}

The atrophied uterine horns observed in SF, D, and 4-MBC groups confirmed successful ovariectomy. Neither D nor 4-MBC given orally exhibited estrogenic activity on the uterus confirming the results obtained previously (Picherit et al. 2000, Seidlová-Wuttke et al. 2006). Oral administration of estrogen induced an uterotrophic activity increasing uterine weight in Ovx rat (Mohamed \& Abdel-Rahman 2000). The advantage of the oral administration of food supplements instead of being injected is that this method is non-invasive and painless for the animals and does not require specialized consumables (syringes etc.) or personnel training. It is near to clinical practice as well. Moreover, $4-\mathrm{MBC}$ has been administered orally or per dermal application in rat so far (reviewed by Schlumpf et al. 2008). Although during the first 3 weeks dosages of the substances enhanced with increasing food intake, during further feeding the dosages remained unchanged at a desirable level (Schlumpf et al. 2001, Vortherms 2006). Measurements of food intake were limited to the period after osteotomy was done. However, it could be suggested that food intake decreased during the first days after osteotomy and then rose recovering to its level (from 8 to $15 \mathrm{~g} / \mathrm{rat}$ per day in average respectively). This assumption is supported by other results showing that food intake of the intact and Ovx Sprague-Dawley rats of 3 to 6 months of age ranged from 16 to $18 \mathrm{~g} /$ rat per day (Wronski et al. 1987, Vortherms 2006).

The lower food intake observed during the first weeks after osteotomy presumably resulted in the weight loss of the rats. Additionally, a reduced physical activity can cause disuse atrophy in muscle (Machida \& Booth 2004) and bone loss (Everett \& Gilligan 1991) that along with lower food intake may also reduce the BW. As previously reported, experimental procedures needed for fracture and fixation in rats are easily tolerated by the animals and they resume normal movement immediately after recovering from anesthesia (Bak \& Jensen 1992). However, we observed subjectively the reduction in physical activity during first days after osteotomy, probably because of the residual pain and/or of the intraoperatively received neuroleptic drug.

Food intake and weight of the rats were observed to be different between the treatment groups. Estrogen fed animals consumed less than others (13 vs $15 \mathrm{~g} /$ rat per day respectively) which is in accordance with previous studies (Piccone $e t$ al. 2004). This may contribute to the lowest BW in these rats, but is not the only reason. According to Toth et al. (2001) ovarian hormones affected body composition independently of changes in food intake. A reduced physical activity in Ovx animals (Wade 1972, Kadi et al. 2002) may have an impact on the recorded differences in the BW. A significantly lower weight was recorded in 4-MBC group compared with osteoporotic group. In D group, it was also lower, however, not significantly. It may be explained by the mild (Schlumpf et al. 2001, Vortherms 2006), but probably different estrogenlike effect of these substances on the metabolism and physical activity. Mueller et al. (2003) reported that 4-MBC at low doses is able to induce activity of estrogen receptors $\alpha$ and $\beta$ in vitro with a lower estrogenic potency compared with phytoestrogens. For the rapid increase in BW (about $100 \mathrm{~g}$ ) after ovariectomy observed in the beginning of our study, amongst other factors, a general growth of the 3-month old animals may be responsible (Berg \& Harmison 1957).

The fracture healing can be divided into three stages: the inflammatory, reparative, and remodeling. In the animal model used in the present study, the conditions 36 days after fracture corresponded to the reparative stage and 72 days postfracture corresponded to the remodeling stage. At the reparative stage, callus bridges and stabilizes fractured bone ends. Endosteal healing associated with slight periosteal callus formation is typical for fracture healing under stable conditions at the metaphyseal site (Claes et al. 1998). In the present study, endosteal bridging prevailed in estrogen treated rats. The predominance of periosteal callus bridging at the side opposite to the plate in SF, D, and 4-MBC groups may be due to the increased periosteal growth of cortical bone reported for Ovx rats (Turner et al. 1987). Additionally, micromovements may occur despite the biomechanically stable fixation and could stimulate callus formation at this side. Micromovement at the fracture site has been shown to be essential for sufficient callus formation (Stuermer et al. 1980). At the end of the experiment, there was an unexpectedly lower rate of complete healing in $\mathrm{E}_{2}$ and 4-MBC group compared with that in other groups. BW in Ovx and D group was higher than in $\mathrm{E}_{2}$ and 4-MBC groups from the second post-fracture week through the subsequent weeks of fracture repair, indicating that the calluses were loaded differently. Increased mechanical load has been reported to promote fracture healing and callus formation (Gardner et al. 2006). High-trabecular connectivity observed during the early stage of fracture healing (36 days) in all treatment groups indicates the capacity of an organism to compensate the potentially negative effect of osteoporosis in fracture healing. After 72 days, however, this capacity is decreased and osteoporotic animals in groups SF, D, and 4-MBC showed poor-trabecular continuity. 


\section{Conclusion}

The phytoestrogen D and u.v. filter 4-MBC react in a similar way to estrogen thereby improving oxidative cell metabolism in muscle when applied at the early stage of fracture healing (36 days). For the late period (72 days) only estrogen treated rats maintained a high- mitochondrial respiration rate. $\mathrm{D}$ and 4-MBC treatments slightly, though not significantly, enhanced muscle fiber size and capillary density in the early phase, but not in the late phase of fracture healing. Thus, D and 4-MBC exert a positive effect on the mitochondria and microstructure of the skeletal muscle during the early stage of osteoporotic fracture healing. Considering their ability to prevent bone loss (Picherit et al. 2000, Seidlová-Wuttke et al. 2006) they may be a chance to revive post-fracture mobilization.

\section{Declaration of interest}

There is no conflict of interest for the research reported.

\section{Funding}

This study was funded by the German Research Society (DFG STU 478).

\section{Acknowledgements}

The authors acknowledge C Kaltwasser, P Ludwig and R Wigger (Institute of Animal Breeding and Genetics, Goettingen, Germany) for expert technical assistance and Prof. W Wuttke, MD and D Seidlová-Wuttke, MD (Department of Endocrinology, University of Goettingen, Goettingen, Germany) for the help in performing ovariectomy and for provision of supplemented diets.

\section{References}

Aloia JF, McGowan DM, Vaswani AN, Ross P \& Cohn SH 1991 Relationship of menopause to skeletal and muscle mass. American Journal of Clinical Nutrition 53 1378-1383.

Andersen P 1975 Capillary density in skeletal muscle of man. Acta Physiologica Scandinavica 95 203-205.

Armstrong RB \& Phelps RO 1984 Muscle fiber type composition of the rat hindlimb. American Journal of Anatomy 171 259-272.

Bak B \& Jensen KS 1992 Standardization of tibial fracture in the rat. Bone 13 289-295.

Berg BN \& Harmison CR 1957 Growth, disease, and aging in the rat. Journal of Gerontology 12 370-377.

Campbell SE \& Febbraio MA 2001 Effect of ovarian hormones on mitochondrial enzyme activity in the fat oxidation pathway of skeletal muscle. American Journal of Physiology. Endocrinology and Metabolism 281 E803-E808.

Claes LE, Heigele CA, Neidlinger-Wilke C, Kaspar D, Seidl W, Margevicius KJ \& Augat P 1998 Effects of mechanical factors on the fracture healing. Journal of Orthopaedic Research 15 577-584.

Everett LS \& Gilligan C 1991 Physical activity effects on bone metabolism. Calcified Tissue International 49 50-54.

Feng X, Li GZ \& Wang S 2004 Effects of estrogen on gastrocnemius muscle strain injury and regeneration in female rats. Acta Pharmacologica Sinica 25 1489-1494.
Gardner MJ, van der Meulen MC, Demetrakopoulos D, Wright TM, Myers ER \& Bostom MP 2006 In vivo cyclic axial compression affects bone healing in the mouse tibia. Journal of Orthopaedic Research 24 1679-1686.

Glazier MG \& Bowman MA 2001 A review of the evidence for use of phytoestrogens as a replacement for traditional estrogen replacement therapy. Archives of Internal Medicine 161 1161-1172.

Haeussler B, Gothe D, Goel D, Glaeske G, Pientka L \& Felsenberg D 2007 Epidemiology, treatment and costs of osteoporosis in Germany - the BoneEVA Study. Osteoporosis International 18 77-84.

Horák V 1983 A successive histochemical staining for succinate dehydrogenase and 'Reversed' - ATPase in a single section for the skeletal muscle fibre typing. Histochemistry and Cell Biology 78 545-553.

Kadi F, Karlsson C, Larsson B, Eriksson J, Larval M, Billig H \& Jonsdottir IH 2002 The effects of physical activity and estrogen treatment on rat fast and slow skeletal muscles following ovariectomy. Journal of Muscle Research and Cell Motility 23 335-339.

Kalu DN 1991 The ovariectomized rat model of postmenopausal bone loss. Bone and Mineral 15 175-192.

Kawano S, Kanda K, Ohmori S, Izumi R, Yasukawa K, Murata Y \& Seo H 1997 Effect of estrogen on the development of disuse atrophy of bone and muscle induced by tail-suspension in rats. Environmental Medicine 41 89-92.

Krinke GJ 2000 The Laboratory Rat, p 756. Ed Bullock \& Bunton. San Diego: Academic press.

Kyriakides ZS, Petinakis P, Kaklamanis L, Sbarouni E, Karayannakos P, Iliopoulos D, Dontas I \& Kremastinos DT 2001 Intramuscular administration of estrogen may promote angiogenesis and perfusion in a rabbit model of chronic limb ischemia. Cardiovascular Research 49 626-633.

Marcus R, Greensdale G, Blunt BA, Bush TL, Sherman S, Sherwin R, Wahner H \& Wells B 1994 Correlates of bone mineral density in the postmenopausal estrogen/progestin intervention trial. Journal of Bone and Mineral Research 9 1467-1476.

Machida S \& Booth FW 2004 Regrowth of skeletal muscle atrophied from inactivity. Medicine and Science in Sports and Exercise 36 52-59.

McClung JM, Davis JM, Wilson MA, Goldsmith EC \& Carson JA 2006 Estrogen status and skeletal muscle recovery from disuse atrophy. Journal of Applied Physiology 100 2012-2023.

Meijer AEFH 1970 Histochemical method for the demonstration of myosin adenosine triphosphatase in muscle tissues. Histochemie 22 51-58.

Mohamed MK \& Abdel-Rahman AA 2000 Effect of long-term ovariectomy and estrogen replacement on the expression of estrogen receptor gene in female rats. European Journal of Endocrinology 142 307-314.

Moline SW \& Glenner GC 1964 Ultrarapid freezing of tissues in liquid nitrogen. Journal of Histochemistry and Cytochemistry 12 777-783.

Moran AL, Nelson SA, Landisch RM, Warren GL \& Lowe DA 2007 Estradiol replacement reverses ovariectomy-induced muscle contractile and myosin dysfunction in mature female mice. Journal of Applied Physiology 102 1387-1393.

Mueller SO, Kling M, Firzani PA, Mecky A, Duranti E, Shields-Botella J, Delansome R, Broschard T \& Kramer PJ 2003 Activation of estrogen receptor alpha and ER beta by 4-methylbenzylidene camphor in human and rat cells: comparison with phyto- and xenoestrogens. Toxicology Letters 142 89-101.

Nilsen J \& Brinton RD 2003 Mechanism of estrogen-mediated neuroprotection: regulation of mitochondrial calcium and Bcl-2 expression. PNAS 100 2842-2847.

Peter JB, Barnard RJ, Edgerton VR, Gillespie CA \& Stempel KE 1972 Metabolic profiles of the three fiber types of skeletal muscle in guinea pigs and rabbits. Biochemistry 11 2627-2633.

Phillips SK, Rook KM, Siddle NC, Bruce CA \& Woledge RC 1993 Muscle weakness in women occurs at an earlier age than in men, but strength is preserved by hormone replacement therapy. Clinical Science 84 95-98.

Piccone CM, Brazeau GA \& McCormick KM 2004 Effect of oestrogen on myofibre size and myosin expression in growing rats. Experimental Physiology 90 87-93.

Picherit C, Coxam V, Bennetau-Pelissero C, Kati-Coulibaly S, Davicco M-J, Lebecque P \& Barlet J-P 2000 Daidzein is more efficient than genistein in preventing ovariectomy-induced bone loss in rats. Journal of Nutrition 130 1675-1681. 
Rahn DA 1976 The fluorochrome sequence labeling of the bone. Nova Acta Leopoldina 44 249-255.

Renner K \& Gnaiger E 2003 High-resolution respirometry with leukemia cells: routine respiration, respiratory control and coupling. Oxygraph-2K Workshop report, Schroecken, Austria. MIPNET 8.9 1-11.

Schlumpf M, Cotton B, Conscience M, Haller V, Steinmannn B \& Lichtensteiger W 2001 In vitro and in vivo estrogenecity of UV screens. Environmental Health Perspectives 109 239-244.

Schlumpf M, Jarry H, Wuttke W, Ma R \& Lichtensteiger W 2004 Estrogenic activity and estrogen receptor beta binding of the UV filter 3-benzylidene camphor. Comparison with 4-methylbenzylidene camphor. Toxicology 199 109-120.

Schlumpf M, Durrer S, Faass O, Ehnes C, Fuetsch M, Gaille C, Henseler M, Hofkamp L, Maerkel K, Reolon S et al. 2008 Developmental toxicity of UV filters and environmental exposure: a review. International Journal of Andrology 31 144-151.

Seidlová-Wuttke D, Jarry H, Christoffel J, Rimoldi G \& Wuttke W 2006 Comparison of effects of estradiol $\left(\mathrm{E}_{2}\right)$ with those of octylmethoxycinnamate (OMC) and 4-methylbenzylidene camphor (4-MBC) - 2 filters of UV light - on several uterine, vaginal and bone parameters. Toxicology and Applied Pharmacology 210 246-254.

Sitnick M, Foley AM, Brown M \& Spangenburg EE 2006 Ovariectomy prevents the recovery of atrophied gastocnemius skeletal muscle mass. Journal of Applied Physiology 100 286-293.

Sorensen MB, Rosenfalck AM, Hojgaard L \& Ottesen B 2001 Obesity and sarcopenia after menopause are reversed by sex hormone replacement therapy. Obesity Research 9 622-626.

Stirone C, Duckles SP, Krause DN \& Procaccio V 2005 Estrogen increases mitochondrial efficiency and reduces oxidative stress in cerebral blood vessels. Molecular Pharmacology 68 959-965.

Stuermer KM, Rack TH \& Kauer F 1980 Intravitale Bewegungsmessung bei der Frakturheilung. Hefte zur Unfallheilkunde 212 489-498.

Stuermer EK, Sehmisch S, Rack T, Wenda E, Seidlova-Wuttke D, Tezval M, Wuttke W, Frosch KH \& Stuermer KM 2008 Estrogen and raloxifene improve metaphyseal fracture healing in the early phase of osteoporosis. A new fracture-healing model at the tibia in rat. Langenbeck's Archives of Surgery (in press) DOI 10.1007/s00423-008-0436-x.

Toth MJ, Poehlman ET, Matthews DE, Tchernof A \& MacCoss MJ 2001 Effects of estradiol and progesterone on body composition, protein synthesis, and lipoprotein lipase in rats. American Journal of Physiology. Endocrinology and Metabolism 280 E496-E501.

Trumbeckaite S, Opalka JR, Neuhof C, Zierz S \& Gellerich FN 2001 Different sensitivity of rabbit heart and skeletal muscle to endotoxininduced impairment of mitochondrial function. European Journal of Biochemistry 268 1422-1429.

Turner RT, Vandersteenhoven JJ \& Bell NH 1987 The effects of ovariectomy and 17 beta-estradiol on cortical bone histomorphometry in growing rats. Journal of Bone and Mineral Research 2 115-122.

Vortherms T 2006 Effects of daidzein, its metabolite equol, puerarin, quercetin and estradiol on the pituitary and the urogenitaltract of the ovariectomized rats. Dissertation Hannover 126 p. (http://deposit. d-nb.de/cgi-bin/dokserv?idn $=98363615 x \&$ dok_var $=$ d1\&dok_ext $=$ pdf\&filename $=98363615 \mathrm{x} . \mathrm{pdf}$ ).

Walsh WR, Sherman P, Howlett CR, Sonnabend DH \& Ehrlich MG 1997 Fracture healing in rat osteopenia model. Clinical Orthopaedics and Related Research 342 218-227.

Wade GN 1972 Gonadal hormones and behavioral regulation of body weight. Physiology and Behavior 8 523-534.

Wang J, Green PS \& Simpkins JW 2001 Estradiol protects against ATP depletion, mitochondrial membrane potential decline and the generation of reactive oxygen species induced by 3-nitroproprionic acid in SK-N-SH human neuroblastoma cells. Journal of Neurochemistry 72 804-811.

Wronski TJ, Lowry PL, Walsch CC \& Ignaszewski LA 1985 Skeletal alterations in ovariectomized rats. Calcified Tissue International 37 324-328.

Wronski TJ, Schenck PA, Cintrón M \& Walsh CC 1987 Effect of body weight on osteopenia in ovariectomized rats. Calcified Tissue International $40155-159$

Yang S-H, Liu R, Perez EJ, Wen Y Jr, Stevens SM, Valencia T, BrunZinkernagel A-M, Prokai L, Will Y, Dykens J et al. 2004 Mitochondrial localization of estrogen receptor $\beta$. PNAS 101 4130-4135.

Received in final form 2 February 2009

Accepted 27 February 2009

Made available online as an Accepted Preprint

2 March 2009 